However, a $50 \%$ increase in the rate of out-of-hospital cardiac arrest was observed during TA. In the cohort of Asthma patients, $74.9 \%$ reported a history of asthma during TA compared with 91.1\% during the comparator period $(p=0.006)$. The most common paramedic intervention for patients with acute respiratory distress was administration of salbutamol (72.5\%) while $8.0 \%$ of patients received adrenaline.

Conclusion The TA event in Melbourne was associated with a significant increase in EMS attendances to patients with acute respiratory illnesses and cardiac arrest.

Conflict of interest None declared.

Funding None declared.

\section{DISPATCH OF FIRE-FIGHTERS AND POLICE OFFICERS IN OUT-OF-HOSPITAL CARDIAC ARREST: A NATIONWIDE PROSPECTIVE COHORT TRIAL}

I Hasselqvist-Axe*, P Nordberg, J Herlitz, L Svensson, M Jonsson, J Lindqvist, M Ringh, A Claesson, J Björklund, JO Andersson, C Ericson, P Lindblad, L Engerström, M Rosenqvist, J Hollenberg. Center for Resuscitation Science, Department of Medicine, Solna, Karolinska Institutet and Section of Cardiology, Södersjukhuset

\subsection{6/bmjopen-2017-EMSabstracts.7}

Aim Dual dispatch of cardiopulmonary resuscitation (CPR) trained fire-fighters or police officers equipped with automated external defibrillators (AEDs) in addition to emergency medical services (EMS) in out-of-hospital cardiac arrest (OHCA) has in some minor cohort studies been associated with improved survival. The aim of this study was to evaluate the association between dual dispatch and survival in OHCA at a national level. Methods This prospective, cohort study was conducted January 1st, 2012, to December 31st, 2014. OHCA victims in nine Swedish counties covered by dual dispatch and resuscitation by first responders and EMSs were compared with a propensity-matched contemporary control group of OHCA victims in 12 counties where only EMS were dispatched. The primary outcome was survival to 30 days.

Results 8698 OHCA were included of which 2786 in each group (intervention and control) were matched. The median time from emergency call to arrival of EMSs or first responder was nine minutes in the intervention group vs. ten minutes in the controls $(\mathrm{p}<0.001)$. The proportion of patients admitted alive to hospital was $31.4 \%$ in the intervention group versus $24.9 \%$ in the controls (adjusted OR 1.40, 95\% CI 1.24-1.57). Thirty-day survival was $9.5 \%$ in the intervention group versus $7.7 \%$ in the controls (adjusted OR 1.27, 95\% CI 1.05-1.54).

Conclusion Dual dispatch of first responders in addition to EMSs in OHCA was associated with a moderate but significant increase in 30 day survival.

\section{REFERENCES}

1. Myerburg RJ, Fenster J, Velez M, Rosenberg D, Lai S, Kurlansky P, Newton S, Knox M and Castellanos A. Impact of community-wide police car deployment of automated external defibrillators on survival from out-of-hospital cardiac arrest. Circulation. 2002;106:1058-64. PMID: 12196329

2. Hollenberg J, Riva G, Bohm K, Nordberg P, Larsen R, Herlitz J, Pettersson H, Rosenqvist $\mathrm{M}$ and Svensson L. Dual dispatch early defibrillation in out-of-hospital cardiac arrest: the SALSA-pilot dagger. European Heart Journal. 2009;30:17811789. doi:10.1093/eurheartj/ehp177.

3. Malta Hansen C, Kragholm K, Pearson DA, Tyson C, Monk L, Myers B, Nelson D, Dupre ME, Fosbol EL, Jollis JG, Strauss B, Anderson ML, McNally B and Granger CB. Association of Bystander and First-Responder Intervention With Survival After Out-of-Hospital Cardiac Arrest in North Carolina, 2010-2013. JAMA: the journal of the American Medical Association. 2015;314:255-64. doi: 10.1001/ jama.2015.7938.
Conflict of interest None declared.

Funding The Swedish Heart-Lung Foundation, the National Board of Health and Welfare, and the Laerdal Foundation for Acute Medicine in Norway.

\section{GENUINE ILLNESS AND INJURY DURING EUROPE'S LARGEST EMERGENCY SERVICE MAJOR INCIDENT EXERCISE}

E Cannon*, T Edwards, R Fothergill. London Ambulance Service, London, UK

\subsection{6/bmjopen-2017-EMSabstracts.8}

Aim Previous studies of patient presentation rates at mass gatherings have been limited to social events. None have assessed presentation rates in the context of a large-scale emergency service exercise where individuals (actors playing hypothetical casualties) are exposed to an environment containing many potential hazards.

Methods Exercise Unified Response was the largest multiagency exercise ever held in Europe. It was a four-day major incident exercise in the UK, in which 2700 individuals acted as casualties. Clinical records completed by healthcare professionals providing on-site medical cover for the duration of the event were reviewed. Clinical records were included where the individual's role in the exercise was listed as 'actor'.

Results Thirty actors required medical attention, giving a patient presentation rate (PPR) of 11.1 per one thousand actors. Of these, $10 \%$ were conveyed to hospital with musculoskeletal $(n=2)$ or head injuries $(n=1)$; an ambulance transfer rate (ATR) of 1.11 per 1000 . Just under half of all patients $(40 \%, n=12)$ had a contributory factor to seeking medical help, where they had: not eaten on the day $(n=4)$; a preexisting condition exacerbated by the exercise, such asthma $(n=3)$; pre-existing symptoms of acute illness $(n=3)$, or a preexisting injury $(\mathrm{n}=2)$.

Conclusion Patient presentation rate was in line with previous research1. However, we believe this is the first study to report similar data for a mass emergency service exercise. Our findings regarding the factors and pre-existing illnesses/conditions that contributed to individuals seeking medical help will be valuable in planning future large-scale exercises.

\section{REFERENCE}

1. Alguthami, A., Pines, J., 2014. A systematic review of noncommunicable health issues in mass gatherings. Prehosp Disaster Med, 29(2), 167-75.

Conflict of interest None declared.

Funding None declared.

\section{AUDIT OF MORPHINE ADMINISTRATION BY EAST MIDLANDS AMBULANCE SERVICE (EMAS)}

S Winter*, R Jootun. East Midlands Ambulance Service

\subsection{6/bmjopen-2017-EMSabstracts.9}

Aim For pre-hospital administration of morphine, JRCALC guidelines recommend recorded pain scores (PS) out of ten before and after use, an anti-emetic adjunct and ENTONOX provision prior to analgesic effect. This audit aimed to gain insight into how rigorously these guidelines were being adhered to in practice 
Methods This clinical audit examined patients who had been administered morphine by EMAS staff. Inclusion criteria were patients who had received documented oral, intravenous or intramuscular morphine within a three-month period. Those who declined morphine were excluded. Data extracted from the patient report forms included: patient demographics; documented PSs; morphine doses and routes; adjunct analgesics and use of anti-emetics. This information was used to determine how appropriately PSs, analgesic adjuncts and antiemetics were being used alongside morphine.

Results There were 293 patients included in the audit. 205 (70.0\%) had a PS documented before and after morphine administration; $50(17.1 \%)$ had one documented PS and 38 (13.0\%) had none. 58 (19.8\%) patients received ENTONOX before the administration of morphine and 17 (5.8\%) received it after morphine. $218(74.4 \%)$ had no record of ENTONOX administration and only $100(34.1 \%)$ patients were prescribed an anti-emetic with morphine.

Conclusion There is potential for improved adherence to JRCALC guidelines through increased awareness and education. We will trial this at EMAS through staff notices followed by a re-audit in 4-6 months. Ideally, audits within other ambulance services with more patients would be undertaken for widespread quality improvement.

\section{REFERENCE}

1. Joint Royal Colleges Ambulance Liaison Committee and Association of Ambulance Chief Executives (2016). UK Ambulance Services Clinical Practice Guidelines 2016. Bridgwater: Class Professional Publishing.

Conflict of interest None declared. Funding None declared.

\section{\begin{tabular}{l|l}
10 & PREHOSPITAL CRITICAL CARE TEAM ATTENDANCE
\end{tabular} INCREASES THE SURVIVAL OF MAJOR TRAUMA PATIENTS: NATIONAL REGISTRY DATA}

\begin{abstract}
${ }^{1} \mathrm{~A}$ Maddock*, ${ }^{2} \mathrm{~A}$ Corfield, ${ }^{3} \mathrm{M}$ Donald, ${ }^{2} \mathrm{~S}$ Hearns, ${ }^{4} \mathrm{R}$ Lyon, ${ }^{5} \mathrm{D}$ Fitzpatrick, ${ }^{5} \mathrm{~N}$ Sinclair. ${ }^{1}$ Anaesthetic Department, Queen Elizabeth University Hospital, Glasgow, UK; ${ }^{2}$ Emergency Department, Royal Alexandra Hospital, Paisley, UK; ${ }^{3}$ Emergency Department, Ninewells Hospital, Dundee, UK; ${ }^{4}$ Emergency Department, Royal Infirmary of Edinburgh, Edinburgh, UK; ${ }^{5}$ Scottish Ambulance Service, Edinburgh, UK

10.1136/bmjopen-2017-EMSabstracts. 10
\end{abstract}

Aim To investigate the effect of prehospital critical care team attendance, versus usual ambulance care, on trauma patient mortality.

Methods We retrospectively examined data from the Scottish Trauma Audit Group for the calendar years 2011-14, covering all trauma patients admitted to hospital in Scotland. We divided them into two groups: those who were seen by a prehospital critical care team; and those who received standard ambulance care only. We compared expected mortality (by TRISS and PS12 models) with observed mortality within each group, with subanalysis of major trauma patients (Injury Severity Score $>15$ ).
Results 10252 patients were available for analysis. Of these, $503(4.9 \%)$ were seen by a prehospital critical care team and 9749 (95.1\%) received standard ambulance care. There was a non significant increase in excess survivors (0.9/100 patients) in the group who received critical care $(p=0.58) .1545$ major trauma patients were available for analysis. Of these, 210 $(13.6 \%)$ were seen by a prehospital critical care team and 1335 (86.4\%) received standard ambulance care. There was a significant increase in excess survivors (4.5/100 patients) in major trauma patients who received critical care $(p=0.03)$.

Conclusion In major trauma patients in Scotland, the addition of prehospital critical care to standard ambulance care results in an increase in patient survival. This study adds to the growing body of evidence supporting the utility of prehospital critical care, especially in the most severely injured patients.

Conflict of interest None declared.

Funding None declared.

\section{INCREASE IN BYSTANDER-CPR IN SWEDEN IS ASSOCIATED WITH INCREASED RATES OF COMPRESSION-ONLY CPR}

${ }^{1} G$ Riva*, IJ Hollenberg, 'L Svensson, ${ }^{1} \mathrm{M}$ Ring, ${ }^{2} \mathrm{~S}$ Rubertsson, ${ }^{1} \mathrm{P}$ Nordberg, ${ }^{1} \mathrm{~A}$ Claesson, ${ }^{1} \mathrm{~T}$ Djärv, ${ }^{3} \mathrm{~J}$ Herlitz. ${ }^{1}$ Karolinska Institute Department of Medicine; ${ }^{2}$ Uppsala Univiversity, Department of Anesthesiology and Intensive Care; ${ }^{3}$ University of Borås, Sweden

\subsection{6/bmjopen-2017-EMSabstracts.11}

Aim To describe changes in rate of CPR, Compression Only CPR (CO-CPR), and 30-day survival over 3 different timeperiods of CPR guidelines in Sweden. We hypothesised that increased use of CO-CPR would be associated with increased CPR-rates and similar survival compared to standard CPR.

Methods Registry based cohort study including all bystander witnessed cases of out-of-hospital cardiac arrests reported to the Swedish register for cardio-pulmonary resuscitation in 2000-2014. Exposure was categorised as bystander CPR or No-CPR. Bystander CPR was further categorised into Standard $\mathrm{CPR}$ with rescue breathing and ventilation (S-CPR) or COCPR. Primary outcome was 30 day survival.

Results 23620 patients were included. Total rates of bystander CPR increased from $36 \%$ in 2000 to $68 \%$ in 2014 . S-CPR increased from $31 \%$ in 2000 to $38 \%$ in 2014. CO-CPR increased from 5\% in 2000 to $30 \%$ 2014. Overall, there was no significant difference in survival among patients receiving CO-CPR or S-CPR (13.6\% vs. $12.9 \% \mathrm{p}=0.3)$.

Conclusion Increase in bystander CPR during the last 15 years in Sweden was associated with an increase in CO-CPR. Overall 30 day survival was not different when comparing COCPR to S-CPR.

Conflict of interest None declared.

Funding None declared. 